Bull. Mater. Sci., Vol. 36, No. 2, April 2013, pp. 301-309. (c) Indian Academy of Sciences.

\title{
Effect of high heating rate on thermal decomposition behaviour of titanium hydride $\left(\mathrm{TiH}_{2}\right)$ powder in air
}

\author{
A RASOOLI*, M A BOUTORABI ${ }^{\dagger}$, M DIVANDARI ${ }^{\dagger}$ and A AZARNIYA \\ Department of Materials Engineering, Faculty of Materials Engineering, University of Tabriz, P.O. Box 5166616471, \\ Tabriz, Iran \\ ${ }^{\dagger}$ School of Metallurgy and Materials Engineering, Iran University of Science and Technology, P.O. Box 16844, Tehran, Iran
}

MS received 22 January 2011; revised 7 January 2013

\begin{abstract}
DTA and TGA curves of titanium hydride powder were determined in air at different heating rates. Also the thermal decomposition behaviour of the aforementioned powder at high heating rates was taken into consideration. A great breakthrough of the practical interest in the research was the depiction of the $\boldsymbol{P}_{\mathrm{H} 2}$-time curves of $\mathrm{TiH}_{2}$ powder at various temperatures in air. In accordance with the results, an increase in heating rate to higher degrees does not change the process of releasing hydrogen from titanium hydride powder, while switching it from internal diffusion to chemical reaction. At temperatures lower than $600{ }^{\circ} \mathrm{C}$, following the diffusion of hydrogen and oxygen atoms in titanium lattice, thin layers $\mathrm{TiH}_{x}$ phase and oxides form on the powder surface, controlling the process. On the contrary, from $700{ }^{\circ} \mathrm{C}$ later on, the process is controlled by oxidation of titanium hydride powder. In fact, the powder oxidation starts around $650{ }^{\circ} \mathrm{C}$ and may escalate following an increase in the heating rate too.
\end{abstract}

Keywords. Titanium hydride; thermal decomposition; thermal analysis.

\section{Introduction}

Gas production of metal hydrides, similar to hydride-phase decomposition process is influenced by the different factors such as hydrogen diffusion within metal lattice, various hydride phases existing in system and the compounds present on metal surface (Gabis et al 2005).

Several distinct models have been proposed to describe the decomposition of metal hydrides. Castro and Meyer (2002) have developed a model based on a three-phase system (Castro and Meyer 2002). They indicated that the hydride spherical particles consist of three layers: (i) $\alpha$-solid solution surface layer, (ii) a thin intermediate layer, including both the solid solution and the hydride at the interface and (iii) a $\beta$-hydride core. The phases do not depend on temperature but rely on the concentration of hydrogen. The model presumes that as the reaction is controlled by one particular process, other processes are going to be in a quasi-equilibrium state. In other words, the reaction is implicitly assumed to be a rapid process. This model implies uniform hydrogen concentration within each region, with no hydrogen content on the particles surface.

The thermal decomposition behaviour of $\mathrm{TiH}_{2}$ powder has been explored by many researchers (Padurets et al 1999; Tsuchiya et al 2002; Bobet et al 2003; Bliznakov et al 2004; Setoyama et al 2005; Yang and Hur 2006; Yang et al 2007).

\footnotetext{
*Author for correspondence (a.rasooli@tabrizu.ac.ir)
}

According to Kennedy and Lopez (2003), for argon, the DTA and TGA curves indicate that the decomposition includes two subsequent stages (Zeppelin et al 2003; Bhosle et al 2003; Kennedy and Lopez 2003; Sandim et al 2005):

$$
\begin{aligned}
& \mathrm{TiH}_{2} \rightarrow \mathrm{TiH}_{X}, \\
& \mathrm{TiH}_{X} \rightarrow \alpha \text {-Ti. }
\end{aligned}
$$

Also, many researchers have investigated the effect of oxidation and heat treatment on the decomposition behaviour of $\mathrm{TiH}_{2}$ powder in air (Kennedy 2002; Kennedy and Lopez 2003; Matijasevic et al 2004; Lehmhus and Rausch 2004; Tsuchiya et al 2005; Matijasevic-Lux et al 2006).

Kennedy and Lopez found out that the oxide layer formation on $\mathrm{TiH}_{2}$ powder reduces the rate of hydrogen emission (Kennedy 2002; Kennedy and Lopez 2003). The oxide formation occurs in the several exothermic stages: at first, oxyhydride forms and eventually $\mathrm{Ti}_{3} \mathrm{O}$ and $\mathrm{TiO}_{2}$ emerged following ensuing heating. This phenomenon indicates that the heat treatment decreases the hydride stoichiometry.

Matijasevic et al (2004) and Matijasevic-Lux et al (2006) showed that the oxide layer forming on the powder surface during the heat treatment acts as a diffusion barrier impeding the hydrogen flow and consequently raises the gas release temperature (Matijasevic et al 2004; Matijasevic-Lux et al 2006).

Tsuchiya et al (2005) contended that the $\delta$-phase titanium hydride is engulfed by an oxide layer $\left(\mathrm{TiO}\right.$ and $\left.\mathrm{TiO}_{2}\right)$ with $10 \mathrm{~nm}$ thickness. Also they found out that hydrogen emits from titanium hydride in a sequence of steps. At first, hydrogen atoms are released from the tetragonal positions of the 
titanium lattice atoms and diffuse from the bulk to the surface. Finally, on the surface, the hydrogen atoms pair up and emit from the particulates surface. The hydrogen content of $\mathrm{TiH}_{2}$ seems to affect the oxidation process. It is suggested that the emission of hydrogen from $\mathrm{TiH}_{2}$ is governed by the first-order rate law.

Lehmhus and Rausch (2004) have annealed $\mathrm{TiH}_{2}$ powder in air and argon. In argon, the powder does not develop a surface layer and as a result, a small amount of hydrogen is lost during annealing. On the particulates heat treated in atmosphere, surface layer is developed, so that it hinders the hydrogen diffusion as a diffusion barrier and affects the desorption of the foaming process also.

Based on liquid-foaming method (ALPORAS), $\mathrm{TiH}_{2}$ powder comes in the molten aluminum at $680{ }^{\circ} \mathrm{C}$ (Miyoshi et al 2000; Duarte and Banhart 2000), so that its temperature increases following that, a large amount of hydrogen releases (Zeppelin et al 2003). Therefore, the study into the heating rate effect on the thermal decomposition behaviour of $\mathrm{TiH}_{2}$ powder is an essential step for bringing the aluminum foam products processing under control.

In the present research, the effect of heating rate on the thermal decomposition behaviour of $\mathrm{TiH}_{2}$ powder in air has been taken into consideration.

\section{Experimental}

The as-received $\mathrm{TiH}_{2}$ powder (Merck, $+98 \%$ purity), with particle size ranging from 2 to $12 \mu \mathrm{m}$, was characterized according to general appearance, using a scanning electron microscope (Philips Model XL30, The Netherlands) to be fit by energy dispersive spectrum (EDS). Also the XRD diffraction was carried out to estimate the phase content in as-received powder. The size distribution of the as-received powder was assessed, using a laser particle-sizer (analysette 22, Germany).

The thermal decomposition behaviour of $\mathrm{TiH}_{2}$ powder, in the presence of the air, was analysed, by differential thermal analysis (DTA) and thermogravimetric analysis (TGA) (Shimadzu DTG60H, Japan). The DTA and TGA curves were obtained at the heating rates of $5,10,20,25$ and $30{ }^{\circ} \mathrm{C} / \mathrm{min}$.

Taking the DTA curves obtained for heating rate of $10{ }^{\circ} \mathrm{C} / \mathrm{min}$ into consideration, it was recognized that hydrogen emission from titanium hydride lattice occurs during seven stages corresponding to temperatures of $285,460,550$, 650,720 and $825^{\circ} \mathrm{C}$, respectively if the process is carried out in the presence of air. XRD patterns of $\mathrm{TiH}_{2}$ heat treated in air was determined using a Netherlands-made platinum-cell diffractometer (Philips Model, The Netherlands) in order to determine phases and compounds formed at the temperatures corresponding to DTA peaks.

The XRD sample consisted of $5 \mathrm{mg}$ titanium hydride heat treated at heating rate of $10{ }^{\circ} \mathrm{C} / \mathrm{min}$ and left for $10 \mathrm{~min}$ at any temperature.

In order to examine the thermal decomposition behaviour of $\mathrm{TiH}_{2}$ powder, in high heating rate, setup was used to measure the pressure of hydrogen online.

After installation of the setup (figure 1), in the first stage, an end-closed AISI 304 stainless steel pipe, with no $\mathrm{TiH}_{2}$ powder content, was entered into the furnace at temperatures of 400, 500, 600, 700, 800, 900 and $1000{ }^{\circ} \mathrm{C}$ and the pressure of the air inside pipe $\left(P_{\text {air }}\right)$ was measured at various temperatures. In the second stage, the same procedure was applied unless an end-closed AISI 304 stainless steel pipe containing $0.1 \mathrm{~g} \mathrm{TiH}_{2}$ powder was entered into the furnace and the pressure of the gas inside the pipe $\left(P_{\text {total }}\right)$ was determined at various temperatures. The hydrogen gas pressure $\left(P_{\mathrm{H}_{2}}\right)$ in each temperature was calculated as follows (3):

$$
P_{\mathrm{H}_{2}}=P_{\text {total }}-P_{\text {air }} \text {. }
$$

After putting $\mathrm{TiH}_{2}$ powder inside the furnace, the retained titanium hydride powder was considered for studying the phases and compounds formed on the powder particles surface by means of X-ray diffraction method (JEOL, Jeoljdx-8030).

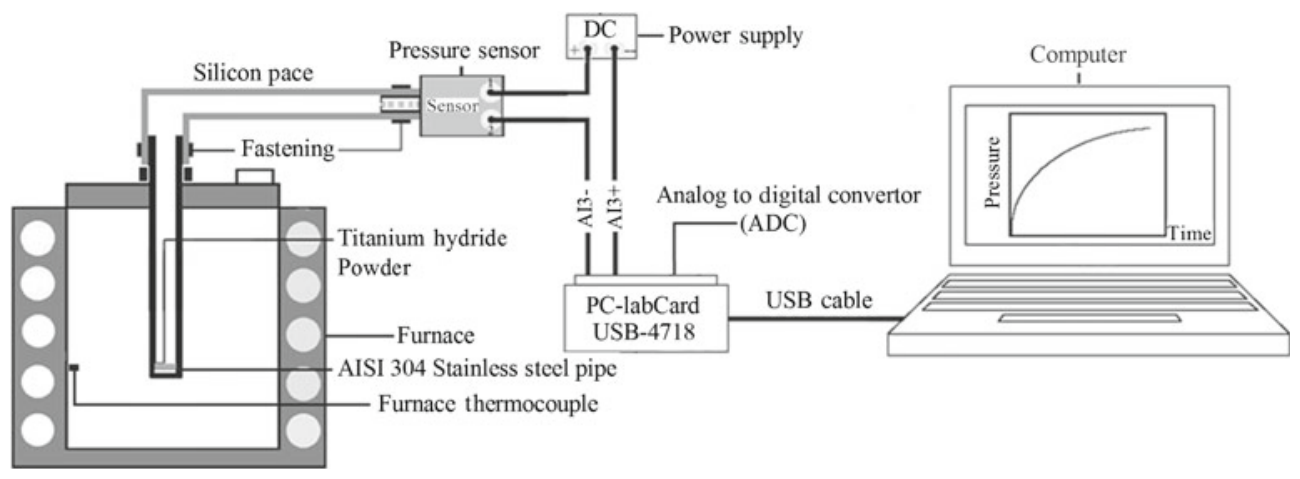

Figure 1. Schematic setup for online measurement of gas pressure. 


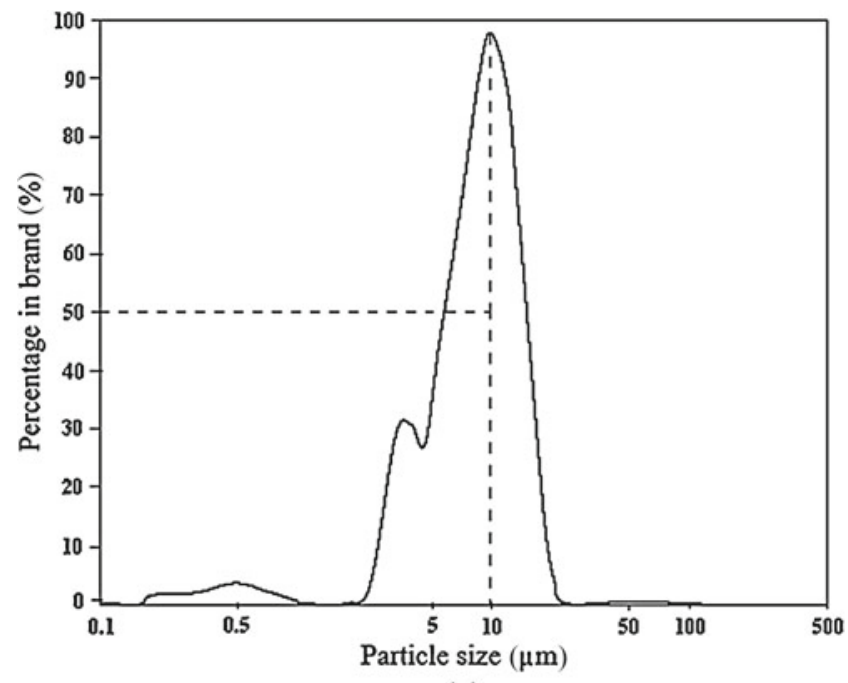

(a)

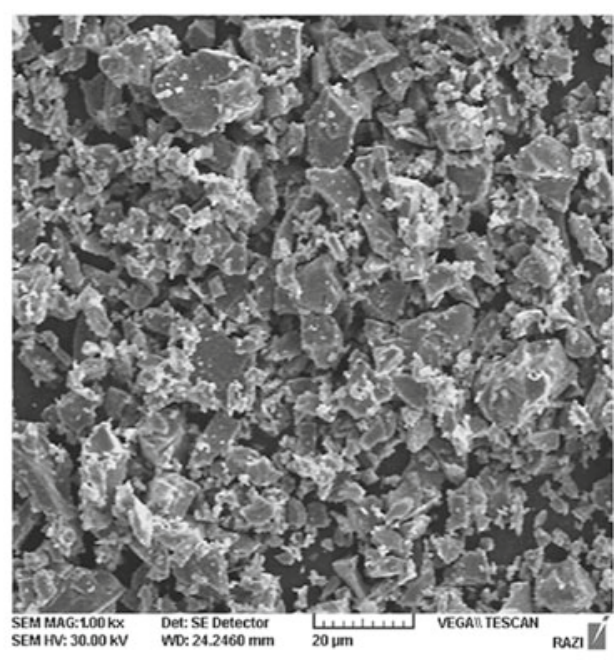

(b)

Figure 2. (a) Particle-size distribution of as-received titanium hydride powder and (b) its corresponding SEM image.

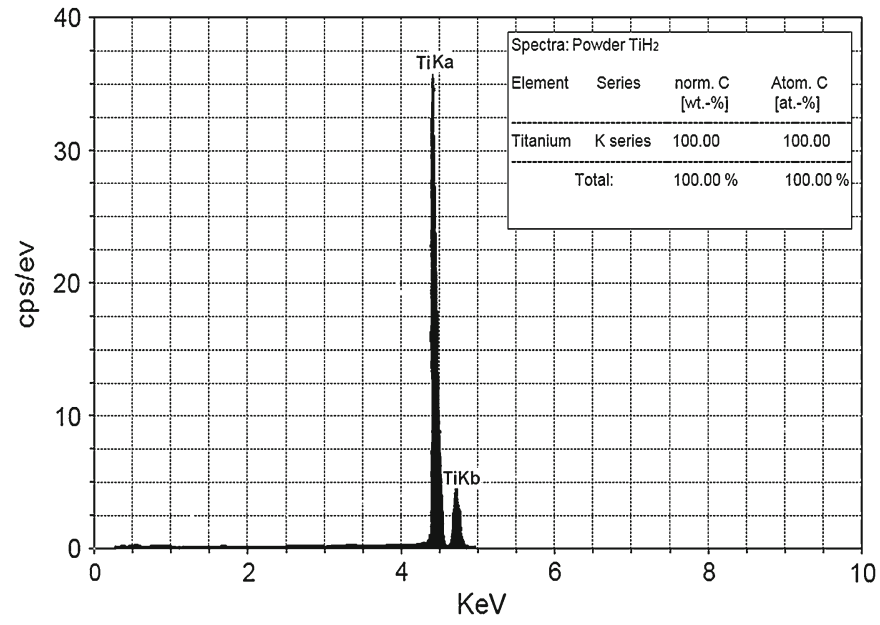

(a)

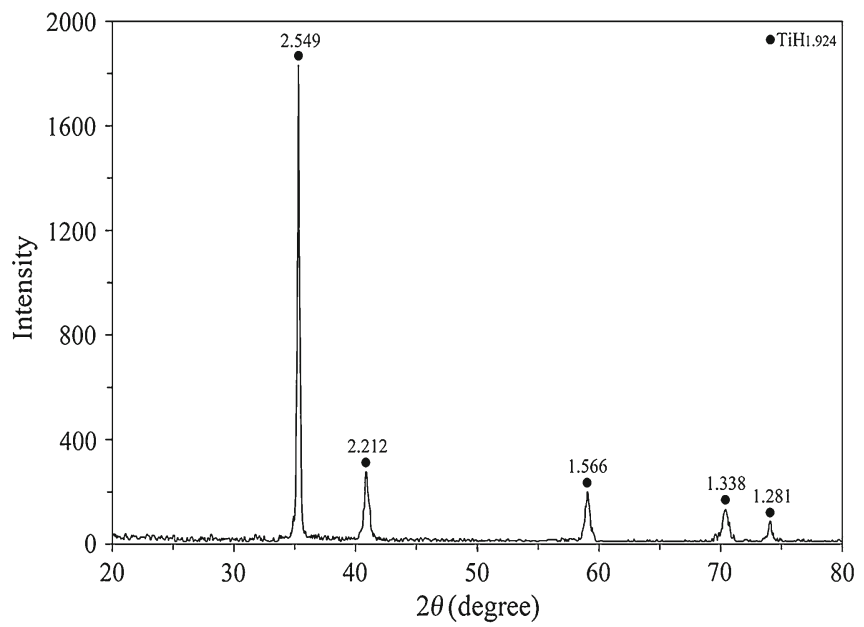

(b)

Figure 3. (a) EDAX spectrum and (b) X-ray diffraction pattern of as-received titanium hydride powder.

\section{Results and discussion}

\subsection{Titanium hydride powder characteristics}

Figure 2 shows particle-size distribution analysis and the SEM image of the as-received $\mathrm{TiH}_{2}$ powder. According to the particle-size distribution analysis, the mean size of the powder is about $8-12 \mu \mathrm{m}$. Also the corresponding SEM image is shown in figure $2(\mathrm{~b})$.

Figure 3 shows chemical analysis, by energy dispersive spectroscopy (EDS) and X-ray diffraction scan of the asreceived $\mathrm{TiH}_{2}$ powder, respectively. According to figure 3, titanium is the only detectable element and no main impurity is revealed in the as-received $\mathrm{TiH}_{2}$ powder (figure 3(a)).
The XRD pattern indicates that the state of hydrogenation is $\mathrm{TiH}_{1.924}$ for the as-received titanium hydride powder (figure 3(b)).

\subsection{DTA analysis}

The DTA curves of $\mathrm{TiH}_{2}$ powder is heat treated in air at various heating rates as shown in figure 4.

According to this figure, the DTA curves for $\mathrm{TiH}_{2}$ powder show a similar trend. In conformity with literature (Meisel and Cote 1983; Sánchez-Jiménez et al 2008), they imply that the mechanism of hydrogen emission is alike at different heating rates. As a result, the hydrogen release mechanism does not change with increase in heating rates. 


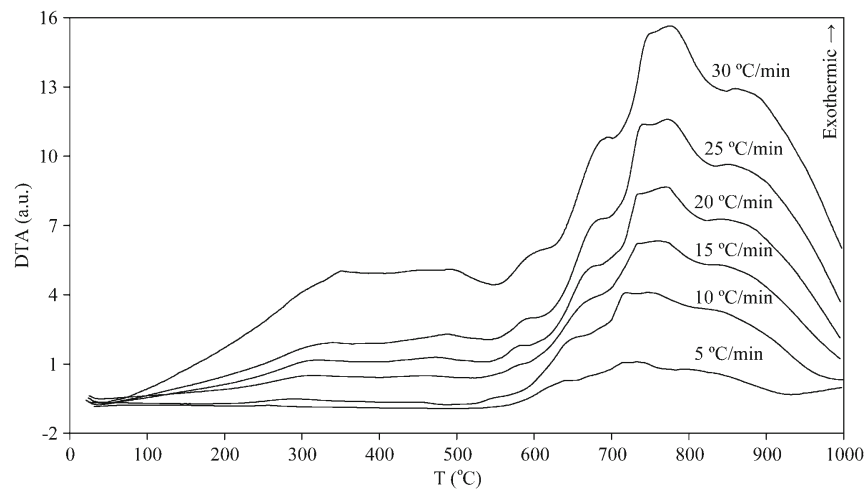

Figure 4. DTA curves of $\mathrm{TiH}_{2}$ powder heated in air at heating rates of $5,10,20,25$ and $30^{\circ} \mathrm{C} / \mathrm{min}$.

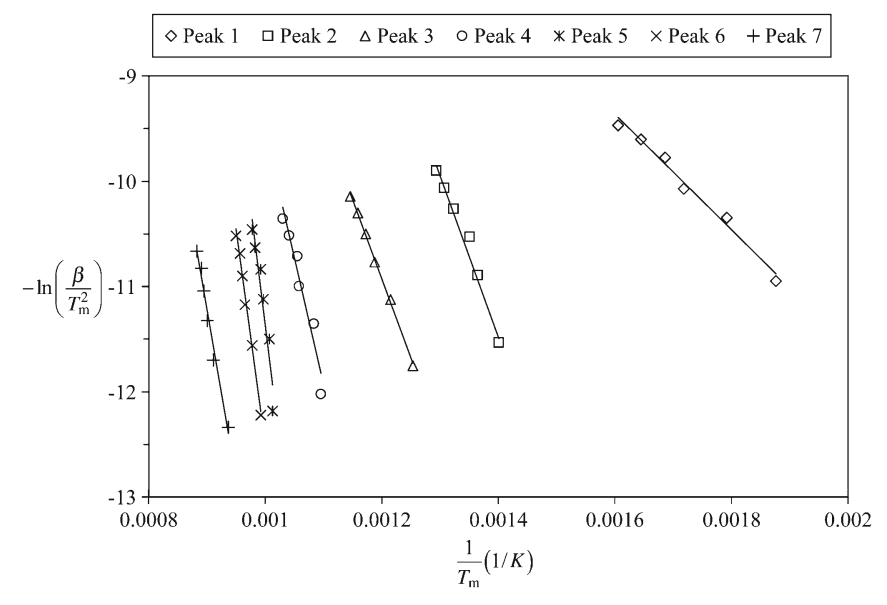

Figure 5. Kissinger plots for seven peaks.

Table 1. Peak temperatures in DTA curves of $\mathrm{TiH}_{2}$ powder at different heating rates.

\begin{tabular}{|c|c|c|c|c|c|c|}
\hline \multirow{3}{*}{$\begin{array}{l}\text { Peak } \\
\text { no. }\end{array}$} & \multicolumn{6}{|c|}{ Peak temperature $\left({ }^{\circ} \mathrm{C}\right)$} \\
\hline & \multicolumn{6}{|c|}{ Heating rate } \\
\hline & $5^{\circ} \mathrm{C} / \mathrm{min}$ & $10^{\circ} \mathrm{C} / \mathrm{min}$ & $15^{\circ} \mathrm{C} / \mathrm{min}$ & $20^{\circ} \mathrm{C} / \mathrm{min}$ & $25^{\circ} \mathrm{C} / \mathrm{min}$ & $30^{\circ} \mathrm{C} / \mathrm{min}$ \\
\hline 1 & 260 & 285 & 310 & 320 & 335 & 350 \\
\hline 2 & 441 & 460 & 465 & 483 & 492 & 500 \\
\hline 3 & 525 & 550 & 580 & 580 & 590 & 600 \\
\hline 4 & 640 & 650 & 670 & 675 & 688 & 698 \\
\hline 5 & 715 & 720 & 740 & 735 & 745 & 750 \\
\hline 6 & 735 & 750 & 765 & 768 & 772 & 780 \\
\hline 7 & 795 & 825 & 840 & 845 & 850 & 860 \\
\hline
\end{tabular}

The DTA curves show roughly different manners in lower and higher than $650{ }^{\circ} \mathrm{C}$ in accordance with literature (Zeppelin et al 2003). It shows that the process of hydrogen emission is different at the two temperature ranges. The maximum intensity of peaks in the DTA curves is seen at temperatures between 735 and $780{ }^{\circ} \mathrm{C}$. Therefore, the maximum rate of transformations is situated in this range (Criado and Ortega 1987). According to our results, the hydrogen gas is released from titanium hydride during seven stages. The temperatures of appeared peaks in the DTA curves for titanium hydride powder at various heating rates are shown in table 1.

According to table 1 , the temperatures corresponding to peaks in the DTA curves increase by raising the heating rate. As literature verifies (Kissinger 1956, 1957), it indicates that the transformations are temperature dependent. The activation energy for the processes has been estimated by the Kissinger relation (4) (Kissinger 1956, 1957) as shown below:

$$
\frac{d\left(\ln \frac{\beta}{T_{\mathrm{m}}^{2}}\right)}{d\left(\frac{1}{T_{\mathrm{m}}}\right)}=-\frac{E}{R},
$$

where $E$ is the activation energy for the transformation, $\beta$ the heating rate, $T_{\mathrm{m}}$ the peak temperature and $R$ the gas constant.

Activation energies may be estimated from the plot of $\left(\ln \beta / T_{\mathrm{m}}^{2}\right)$ vs $\left(1 / T_{\mathrm{m}}\right)$ (figure 5$)$.

Figure 5 presents the Kissinger plots for the seven transformations. The activation energies derived from this plot are 45, 127, 124, 200, 377, 340 and $268 \mathrm{~kJ} / \mathrm{mole}$, respectively. As implied, with an increase in temperature, the activation energy of the $\mathrm{TiH}_{2}$ powder transformations also increases.

A primary investigation in XRD patterns of $\mathrm{TiH}_{2}$ obtained for temperatures corresponding to seven DTA peaks (as presented in figure 6) indicates that at first appearance, $\delta$ $\mathrm{TiH}_{X}$ film forms on the $\mathrm{TiH}_{2}$ particulate surfaces and following that, the powder sample loses its weight. It implies that hydrogen atoms are emitted from titanium lattice. With an increase in temperature, $\mathrm{Ti}_{3} \mathrm{O}$ layers start forming on the particle's surface, as alongside hydrogen emission, a small amount of oxygen atoms entered within titanium lattice too. By further increase in temperature, diverse titanium oxides with higher hydride stoichiometry start to form on powder particulate surfaces, because 




Figure 6. XRD patterns of heated $\mathrm{TiH}_{2}$ powder heated with $10{ }^{\circ} \mathrm{C} / \mathrm{min}$ in air at $25,285,460$, $550,660,720,750$ and $825^{\circ} \mathrm{C}$ temperatures.

both hydrogen emission and oxygen entrance flow increases interactively.

This means that the process of hydrogen emission changes from physical process to chemical process. Therefore, it seems that, at lower temperatures such as $600{ }^{\circ} \mathrm{C}$ (1-3 peaks), the emission of hydrogen atoms is controlled by internal diffusion (the diffusion of hydrogen atoms within titanium lattice) and at higher temperatures such as $700{ }^{\circ} \mathrm{C}$ (5th-7th peaks), it is controlled by chemical reaction (oxidation of titanium) where temperature of powder oxidation is almost similar to literature (Kennedy 2002; Lehmhus and Rausch 2004; Matijasevic et al 2004; Gabis et al 2005; Tsuchiya et al 2005; Matijasevic-Lux et al 2006).

\subsection{TGA analysis}

The TGA curves of $\mathrm{TiH}_{2}$ powder in air at various heating rates are shown in figure 7.

According to figure 7, the weight of $\mathrm{TiH}_{2}$ powder may rise during the heating process at different rates. This may be due to the formation of the titanium oxide on the surface of the powder particles. Several researchers reported the formation of oxide on the surface of the powder particulates (Kennedy 2002; Kennedy and Lopez 2003; Matijasevic et al 2004; Lehmhus and Rausch 2004; Tsuchiya et al 2005; Matijasevic-Lux et al 2006).

Between the TGA curves, at various heating rates, it is revealed that there are some partial changes within 


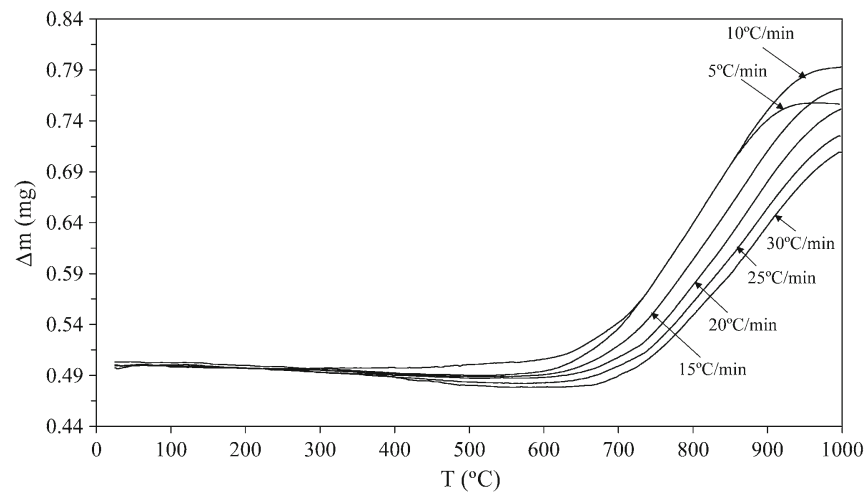

Figure 7. TGA curves of $\mathrm{TiH}_{2}$ powder heated in air at heating rates of $5,10,20,25$ and $30^{\circ} \mathrm{C} / \mathrm{min}$.

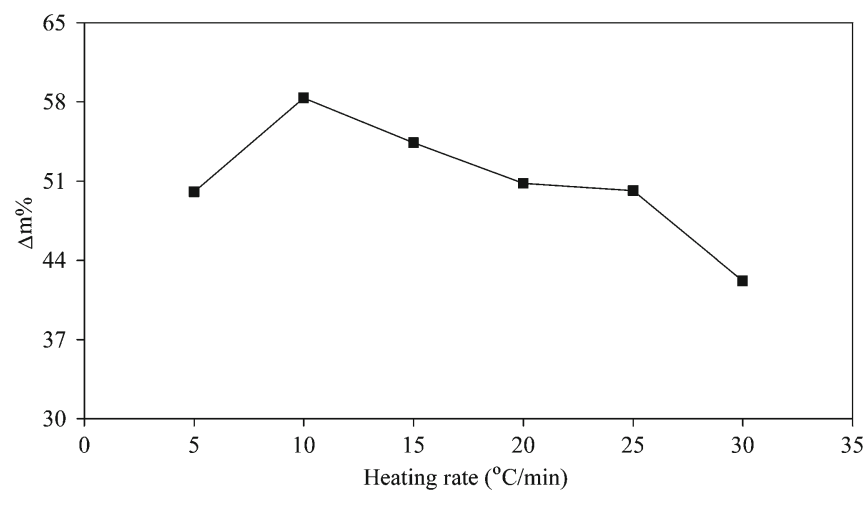

Figure 8. Final wt $\%$ of titanium hydride powder at different heating rates.

temperatures of 300 to $650{ }^{\circ} \mathrm{C}$. According to the results, the weight of the powder increases as the temperature rises.

The TGA curves are alike while the TGA curves show different manners almost lower and higher than $650^{\circ} \mathrm{C}$. This matter shows that the mechanism of hydrogen emission from titanium hydride is different.

According to gas production of metal hydrides (Gabis et al 2005), Castro and Meyer model of metal hydrides (Castro and Meyer 2002) and thermal decomposition of $\mathrm{TiH}_{2}$ powder in argon (Zeppelin et al 2003; Bhosle et al 2003; Kennedy and Lopez 2003; Sandim et al 2005), it seems that at temperatures lower than $650{ }^{\circ} \mathrm{C}$, the weight of powder increases a little, because of the emission of hydrogen atoms from titanium lattice and the formation of $\delta-\mathrm{TiH}_{X}$ layer on the powder particles surface so that when heating rate increases, the thickness of $\delta-\mathrm{TiH}_{X}$ layer also increases.

At temperatures higher than $650{ }^{\circ} \mathrm{C}$, it seems that the oxygen atoms, at first stage, enter the titanium lattice, leading to the formation of the oxy-hydride layer and finally the oxide layer is formed on the powder particles' surface in accordance with literature (Kennedy 2002; Kennedy and Lopez 2003), so the powder weight increases. The study of the TGA curves has shown that the final weight percent changes by increasing the heating rate (figure 8).

According to figure 8 , as the heating rate rises, the final weight percent increases from 5 to $10^{\circ} \mathrm{C} / \mathrm{min}$ and decreases from 10 to $30^{\circ} \mathrm{C} / \mathrm{min}$.

The process is probably an internal diffusion control (the diffusion of hydrogen and oxygen atoms along the surface layers), just because of the formation of solid solution $\alpha$ and oxide layer on the powder particles' surface (Kennedy 2002; Kennedy and Lopez 2003; Matijasevic et al 2004; Lehmhus and Rausch 2004; Sandim et al 2005; Tsuchiya et al 2005; Matijasevic-Lux et al 2006). Therefore, the needed time for the diffusion of oxygen atoms within the surface layers decreases by increasing the heating rate. Consequently, the lower amounts of titanium oxide are formed on the powder particles' surface and the powder weight increases.

\subsection{Online measurement of hydrogen gas pressure evolution}

Figure 9 shows measured hydrogen gas pressure at various temperatures vs elapsed time.

In figure 10, the XRD patterns of retained $\mathrm{TiH}_{2}$ powder, after heating at various temperatures, are presented. The XRD patterns prove that the formation of titanium oxide phase is due to $\mathrm{TiH}_{2}$ powder heating process.

According to figure 9, at the temperatures lower than $600{ }^{\circ} \mathrm{C}$ and higher than $700{ }^{\circ} \mathrm{C}$, released hydrogen gas presents different behaviours. The results are in accordance with the DTA and TGA curves (figures 4 and 7).

At the lower temperatures of $600{ }^{\circ} \mathrm{C}$, the hydrogen gas pressure changes parabolically as time passes. In this temperature range, the emission of hydrogen gas occurs in one stage. Small quantities of hydrogen come out of titanium hydride, because the maximum hydrogen gas pressure is 110 mbar. In this temperature range, by passing time and increasing $\delta$ - $\mathrm{TiH}_{X}$ layer thickness, the hydrogen gas pressure has increased and then a constant is reached.

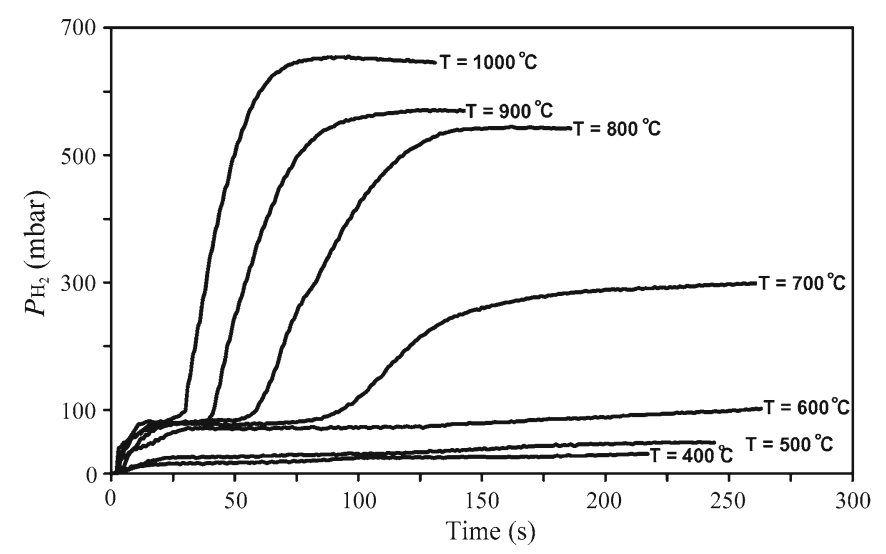

Figure 9. $P_{\mathrm{H}_{2}}$-time curves at various temperatures. 
As shown in figure 10 , at $400{ }^{\circ} \mathrm{C}$, a layer of $\delta-\mathrm{TiH}_{X}$ has been formed (5) on the powder particles' surface due to the release of hydrogen atoms from titanium lattice (Bhosle et al 2003; Kennedy and Lopez 2003; Sandim et al 2005). This results in an increase in hydrogen gas pressure up to about 40 mbar.

$$
\mathrm{TiH}_{2} \rightarrow \mathrm{TiH}_{X}+(2-x) / 2 \mathrm{H}_{2} .
$$

Furthermore, the XRD patterns analysis shows that the peak intensities pertinent to titanium hydride decrease, being indicative of hydrogen atoms emission from titanium lattice.

According to figure 10, at the temperatures of 500 and $600{ }^{\circ} \mathrm{C}$, the peak intensities of titanium hydride decrease and oxide peaks are hardly recognizable in the XRD patterns, meaning that oxide layer extends on the powder particles' surface after $600{ }^{\circ} \mathrm{C}$.

At temperatures higher than $700{ }^{\circ} \mathrm{C}$, more titanium hydride decomposes, increasing the hydrogen gas pressure up to 310 mbar. In this temperature, the change of hydrogen gas pressure vs time is complex and the hydrogen release is accomplished during two stages. At first stage, the hydrogen gas pressure increase to about 83 mbar, remaining unchanged for a long time. Then it increases again and eventually, a certain point is reached in which hydrogen gas pressure remains unchanged until the end of the experiment.

In fact, in the first stage, the emission of hydrogen from $\mathrm{TiH}_{2}$ is accomplished at a relatively constant rate for different temperatures and hydrogen pressure increases parabolically (6).

$$
\left(P_{\mathrm{H}_{2}}\right)^{2}=K \times t,
$$

where $P_{\mathrm{H}_{2}}$ is hydrogen gas pressure, $K$ the rate constant and $t$ the time.

The rise in furnace temperature from 700 to $1000{ }^{\circ} \mathrm{C}$ increases the rate constant $(K)$ while the time of unchanged pressure decreases. As a steady state for gas pressure is reached, the second stage starts. In the first step, the equation rate of the $\mathrm{TiH}_{2}$ powder decomposition reaches to zero order. In the second step, the rate equation is recognized parabolically (6).

According to Arrhenius equation (7) (Galwey and Brown 1995), the activation energies of the first stage and the first

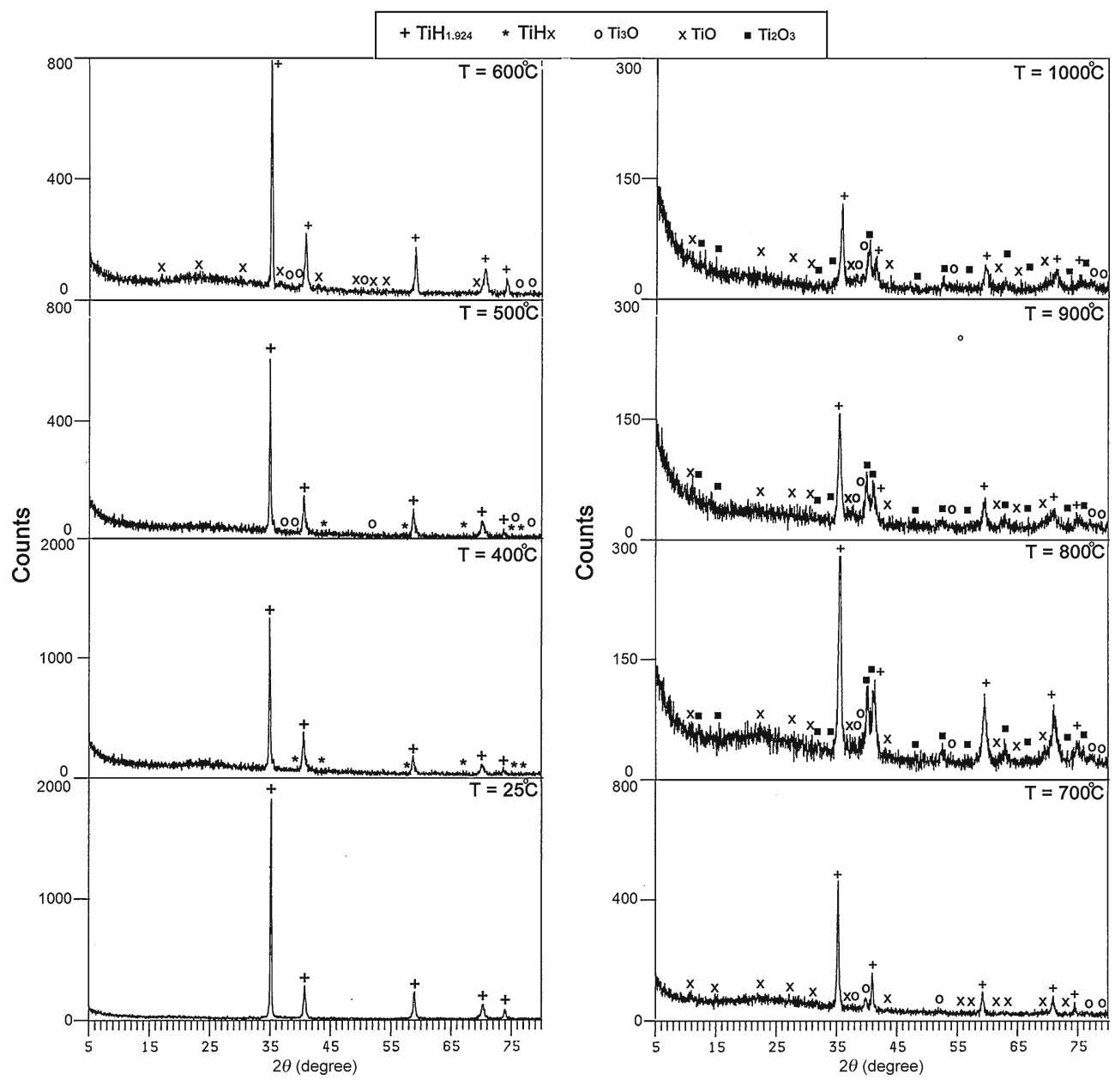

Figure 10. XRD patterns of heated $\mathrm{TiH}_{2}$ powder at $25,400,500,600,700,800,900$ and $1000{ }^{\circ} \mathrm{C}$. 
and the second steps of the second stages were almost determined as 45, 60 and $79 \mathrm{~kJ} / \mathrm{mol}$, respectively (figure 11).

$$
K=A \cdot \exp \left(-\frac{Q}{R \times T}\right),
$$

where $A$ is the frequency factor, $Q$ the activation energy, $R$ the gas constant, $T$ the absolute temperature and $K$ the rate constant.

The study of XRD patterns at temperatures between 700 and $1000{ }^{\circ} \mathrm{C}$ (figure 10) shows that the peaks of titanium oxides appears more significant than at temperatures lower than $600{ }^{\circ} \mathrm{C}$. The formation of titanium oxide on the powder particle surface results in the unchanged pressure of the hydrogen gas at temperatures higher than $700^{\circ} \mathrm{C}$. By increasing temperature, the intensity of titanium oxide peaks $\left(\mathrm{Ti}_{3} \mathrm{O}\right.$, $\mathrm{TiO}$ and $\mathrm{Ti}_{2} \mathrm{O}_{3}$ ) decreases (figure 10) and like the TGA curves (figure 7), the formation of oxide phase on the powder particles' surface reduces. Thereupon, the hydrogen gas pressure is fixed for a short time. Following that, hydrogen atoms are accumulated under the oxide layer because of their emission from the titanium lattice (Bhosle et al 2003). It seems that as solid state changes, the layer cracks and channels are formed within. Consequently, the hydrogen gas pressure increases again. But in accordance with the DTA curves, the layer does not crack because of slower diffusion process of hydrogen gas.

Generally, regarding the $P_{\mathrm{H}_{2}}$-time curves in figure 9 and the XRD patterns in figure 10 , it can be concluded that the change of the hydrogen emission mechanism may happen between temperatures 600 and $700{ }^{\circ} \mathrm{C}$. In this temperature range, the oxide layer forms on the powder particles' surface and the hydrogen emission mechanism changes.

It may be inferred from the DTA and TGA curves (figures 4 and 7) that the change of the hydrogen emission mechanism occurs at temperatures between 640 and $700{ }^{\circ} \mathrm{C}$ (peak 4). As the DTA curves present in most of the important peaks are appeared from $650{ }^{\circ} \mathrm{C}$ later on. The weight of

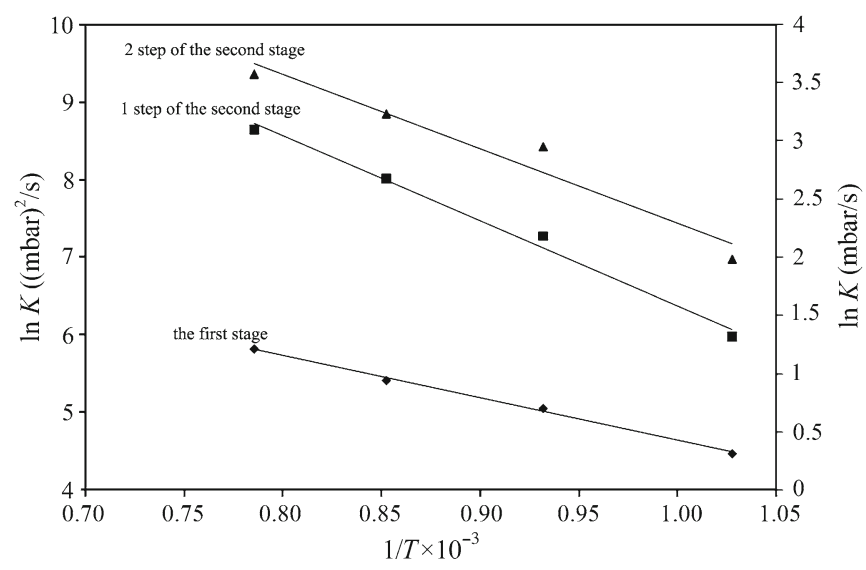

Figure 11. Arrhenius plot for first stage and for first and second steps of second stages. the powder increases at $650{ }^{\circ} \mathrm{C}$ in the TGA curves, indicating the formation of titanium oxide on the powder particles' surface.

Similar results will be obtained by comparing different thermal decomposition kinetics of titanium hydride powder by means of thermal analysis apparatus and a designed system too.

Finally, it seems that the emission mechanism of hydrogen from the titanium lattice does not change at a high heating rate.

\section{Conclusions}

(I) The hydrogen gas is released from titanium hydride in air during seven stages. (II) With an increase in heating rate to the upper rates, the process of hydrogen emission from titanium hydride does not change. (III) At temperatures between 600 and $700{ }^{\circ} \mathrm{C}$, the hydrogen emission mechanism from titanium hydride changes during heating of titanium hydride powder in air. (IV) At temperatures lower than $600{ }^{\circ} \mathrm{C}$ and higher than $700{ }^{\circ} \mathrm{C}$, the mechanism is controlled by internal diffusion and chemical reaction, respectively. (V) The maximum rate of chemical reaction occurs at temperatures between 730 and $760{ }^{\circ} \mathrm{C}$. (VI) Powder oxidation starts around $650{ }^{\circ} \mathrm{C}$ and by increasing the heating rate, its temperature rises too. (VII) By increasing temperature in the $P_{\mathrm{H}_{2}}$-time curves or by raising the heating rate in the TGA curves, the formation of oxide phase on the powder particles' surface, reduces.

\section{References}

Bhosle V, Gaburaj E G, Miranova M and Salama K 2003 Mater. Eng. A356 190

Bliznakov S, Lefterov E, Bozukov L, Popov A and Andreev P 2004 Techniques for characterization of hydrogen absorption/desorption in metal hydride alloys, Proceedings of the international workshop "advanced techniques for energy sources, investigation and testing” (Sofia, Bulgaria)

Bobet J L, Even C and Quenisset J M 2003 J. Alloys Compd. 348 247

Castro F and Meyer G 2002 J. Alloys Compd. 33059

Criado J M and Ortega A 1987 Acta Metall. 351715

Duarte I and Banhart J 2000 Acta Mater. 482349

Gabis J E, Voit A P, Evard E A, Zaika Yu V, Chernov I A and Yartys V A 2005 J. Alloys Compd. 404312

Galwey A K and Brown M E 1995 Proc. R. Soc. Lond. A450 510

Kennedy A R 2002 Scripta Materiala 47763

Kennedy A R and Lopez V H 2003 Mater. Sci. Eng. A357 258

Kissinger H E 1956 J. Research National Bureau Standards 57217

Kissinger H E 1957 Anal. Chem. 291702

Lehmhus D and Rausch G 2004 Adv. Eng. Mater. 6313

Matijasevic B, Fiechter S, Zizak I, Gorke O, Wanderka N, SchubertBischoff P and Banhart J 2004 Decomposition behaviour of asreceived and oxidized $\mathrm{TiH}_{2}$ powder, Powder Metallurgy World Congress (Vienna: European Powder Metallurgy Association)

Matijasevic-Lux B, Banhart J, Fiechter S, Gorke O and Wanderka N 2006 Acta Mater. 541887 
Meisel L V and Cote P J 1983 Acta Mater. 311053

Miyoshi T, Itoh M, Akiyama S, and Kitahara A 2000 Adv. Eng. Mater. 2179

Padurets L N, Dobrokhotova Zh V and Shilov A L 1999 Inter. J. Hydrog. Energy 24153

Sánchez-Jiménez P E, Criado J M and Pérez-Maqueda L A 2008 J. Therm. Anal. Calorim. 94427

Sandim H, Morante B and Suzuki P 2005 Mater. Res. 8293

Setoyama D, Matsunaga J, Ito M, Muta H, Kurosaki K, Uno M and Yamanaka S 2005 J. Nucl. Mater. 344298
Tsuchiya B, Teshigawara M, Nagata S, Konashi K, Yasuda R, Nishino Y, Nakagawa T and Yamawaki M 2002 Nuclear Inst. Meth. Phys. Res. B190 699

Tsuchiya B, Nagata S, Ohtsu N, Toh K and Shikama T 2005 Japan Institute Metals 46196

Yang D H and Hur B Y 2006 Mater. Lett. 603635

Yang D H, Hur B Y, He D P and Yang S R 2007 Mater. Sci. Eng. A445 415

Zeppelin F V, Hirscher M, Stanzick H and Banhart J 2003 Compos. Sci. Tech. 632293 